\title{
Stillbirths: Incidence, Causes and Surrogate Markers of Intrapartum and Antepartum Fetal Deaths
}

\author{
Ojasvi Shanker ${ }^{1}$, Vandana Saini ${ }^{2}$, Mamta Gupta ${ }^{* 3}$ \\ ${ }^{1}$ Astt. Professor, Obst. Gynae Department, Manipal Tata Medical College, Jamshedpur, Jharkhand, India \\ ${ }^{2}$ Sr. Specialist, Obst. Gynae Department, Hindu Rao Hospital \& NDMC Medical College, Delhi, India \\ ${ }^{3}$ Consultant Gynaecologist \& Ex HOD, Obst. Gynae Department, Hindu Rao Hospital \& NDMC Medical College, Delhi, \\ India
}

Corresponding author: Mamta Gupta; write2mamta55@gmail.com

Received 13 July 2020;

Accepted 21 July 2020;

Published 01 August 2020

\begin{abstract}
Background: Stillbirth is a traumatic experience for both the patient and the obstetrician. Determining its cause and early interventions can reduce stillbirths. The study was undertaken to determine the incidence, evaluate causes and surrogate markers for intrapartum and antepartum stillbirths. Methods: A retrospective study was carried out from August 2015 to December 2018. All stillbirths more than 22 weeks or a birthweight of $\geq 500 \mathrm{~g}$ were included in the study. Demographic and all clinical details were collected from the indoor case records and cause of fetal death assigned. Results: There were 520 stillbirths and 28,580 deliveries in the study period. Majority of these women with stillbirths were in the age group of 20-25 years at 33-37 weeks period of gestation, had parity 1 to 3 and were unbooked. Intrapartum deaths accounted for only $8.46 \%$ stillbirths. Extreme prematurity was the most common cause for stillbirths $(20.38 \%)$ followed by chorioamnionitis (16.73\%), hypertensive diseases $(15.77 \%)$ and abruption (10.38). The cause remained unknown in $53.27 \%$. Fetal movement appeared a better surrogate of antepartum /intrapartum deaths than macerated/fresh stillborns. Conclusions: Incidence of stillbirths was $1.8 \%$. Most of the deaths were antepartum (91.53\%). Extreme prematurity was the commonest cause. Fetal movement appeared a better surrogate marker of intrapartum / antepartum deaths.
\end{abstract}

Keywords: Stillbirth rate, Intrapartum stillbirths, Antepartum stillbirths, Antenatal care, Hypertensive diseases in pregnancy, Extreme prematurity, Chorioamnionitis

\section{Introduction}

Stillbirth is an extremely distressing situation for the woman and her family and also for the obstetrician and has profound emotional, social and economic consequences. Various definitions have been given for stillbirth considering fetal weight (500 $1000 \mathrm{gm})$ and gestational age (20 -28 weeks) at which fetal death occurs. ICD 10 defines stillbirth as death of a fetus which weighs $500 \mathrm{~g}$ or more or has reached the gestational age of 22 weeks or has a crown rump length of $25 \mathrm{~cm}^{[1]}$.

Still birth rate (SBR) directly represents the quality of antenatal care of a country ${ }^{[2]}$. In 2015, the worldwide stillbirth rate (SBR) was 18.4 per 1000 total births ${ }^{[3]}$. SBR varies sharply by country, from the lowest rates of 2 per 1000 births in Finland and Singapore and to highest of 47 in Pakistan and 42 in Nigeria ${ }^{[4]}$. India with a SBR of 23 per 1000 births in 2015, is among the top 10 countries with highest stillbirth numbers ${ }^{[5]}$. Amongst various Indian states, SBR varies from 20 to 66 per 1000 births ${ }^{[4]}$.

Fetal death is multifactorial and related to maternal, placental or fetal causes. Certain demographic factors for fetal death are race, low socioeconomic status, less education and advanced maternal age ${ }^{[6]}$. Causes of fetal death like cord accidents have remained unchanged over decades; causes like antiphospholipid antibodies have been recognized only recently ${ }^{[6]}$. Fetal deaths due to $\mathrm{Rh}$ isoimmunization are detectable and preventable. Stillbirths due to chromosomal abnormalities can be reduced with proper antenatal screening. Causes like post maturity, diabetes and pregnancy induced hypertension are also preventable with regular monitoring and timely intervention. Ultrasonography, intrapartum electronic fetal monitoring and partograph are important for reducing stillbirths. Hence, it is important to determine the cause of fetal death and its risk factors so that the woman can be counselled and appropriate steps can be taken to prevent and decrease the incidence of still births.

\section{Aim and Objectives}

The objective of our study was to determine the incidence and cause of stillbirths, and to evaluate surrogate markers of intrapartum /antepartum fetal death. 


\section{Materials and Methods}

This was a retrospective study carried out at Hindu Rao Hospital and associated NDMC Medical College, Delhi, India from August 2015 to December 2018. Data was collected on a proforma from indoor labor room records regarding demographic details of the woman (age, parity, antenatal visits), obstetric details of the present and past pregnancies, gestational age at the time of admission, associated medical and obstetric complications and relevant investigations. Data regarding baby such as birth weight, macerated or fresh still born were also recorded. Most probable cause of fetal death was assigned. Standard protocols were followed for delivery of the fetus. Labor details, mode of delivery was also recorded.

Stillbirth was defined as the birth of a baby with no sign of life after 22 weeks or a birthweight of $\geq 500 \mathrm{~g}^{[1]}$. Booked women were defined as those who had at least 3 antenatal visits. Women

with less than 3 antenatal visits were classified as unbooked. An intrapartum stillbirth included deaths which occured after the onset of labor but before birth. Diagnosis of intrapartum stillbirth was confirmed when fetal heart was present at the onset of labor or at the time of admission in labor ward. Antepartum stillbirth was where death occurred before labor and fetal heart was absent before the onset of labor or at the time of admission in labor ward.

A 'macerated' fetus was defined as one which had skin and soft-tissue changes (skin discoloration or darkening, redness, peeling, and breakdown) suggesting death was well before delivery (ante-partum). A 'fresh' stillborn fetus lacked such skin changes and was presumed to have died much more recently (intrapartum) ${ }^{[7]}$. Still birth rate was defined as the number of stillbirths per 1000 births (live and stillbirths) ${ }^{[8]}$.

\section{Results}

Table 1: Year wise stillbirths $(\mathrm{N}=\mathbf{5 2 0})$

\begin{tabular}{|l|l|l|l|}
\hline Year & Total deliveries & Still births & Stillbirths /1000 (SBR) \\
\hline 2015 & 3566 & 79 & 22.15 \\
\hline 2016 & 8271 & 190 & 22.85 \\
\hline 2017 & 8681 & 134 & 15.55 \\
\hline 2018 & 8062 & 117 & 14.5 \\
\hline Total & 28,580 & 520 & 18.19 \\
\hline
\end{tabular}

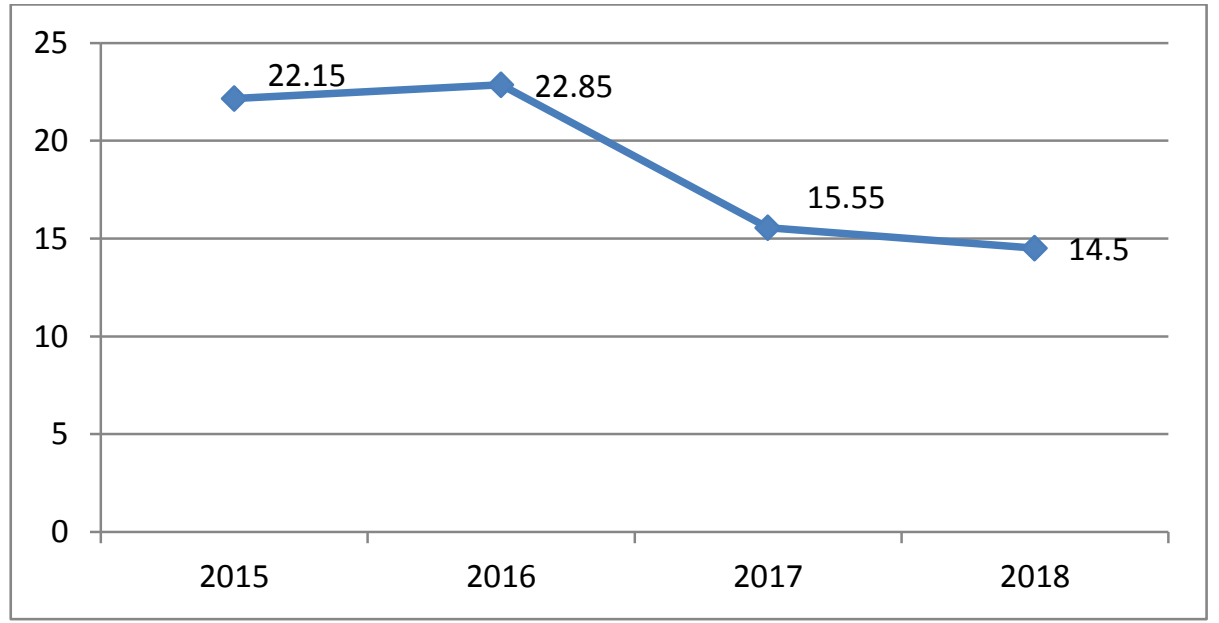

Fig. 1: Trends of SBR from 2015-2018

Table 2: Baseline data $(\mathrm{N}=520)$

\begin{tabular}{|c|c|c|}
\hline Parameter & $\mathrm{n}$ & $\%$ \\
\hline \multicolumn{3}{|l|}{ Maternal age (years) } \\
\hline$<20$ & 16 & $3.07 \%$ \\
\hline $20-25$ & 286 & $55.0 \%$ \\
\hline $26-30$ & 168 & $32.3 \%$ \\
\hline $31-35$ & 43 & $8.27 \%$ \\
\hline$>35$ & 7 & $1.34 \%$ \\
\hline \multicolumn{3}{|l|}{ Parity } \\
\hline Primipara & 210 & $40.38 \%$ \\
\hline Para 2-3 & 305 & $58.65 \%$ \\
\hline Para $>3$ & 5 & $0.96 \%$ \\
\hline \multicolumn{3}{|l|}{ Booking status } \\
\hline Booked & 235 & $45.19 \%$ \\
\hline Unbooked & 285 & $54.81 \%$ \\
\hline \multicolumn{3}{|l|}{ Gestational age (weeks) } \\
\hline$\leq 22$ & 14 & $2.69 \%$ \\
\hline $23-28$ & 92 & $17.69 \%$ \\
\hline $29-32$ & 96 & $18.46 \%$ \\
\hline $33-37$ & 180 & $34.61 \%$ \\
\hline $38-40$ & 122 & $23.46 \%$ \\
\hline$>40$ & 16 & $3.07 \%$ \\
\hline
\end{tabular}


Table 3: Clinical details $(\mathrm{N}=520)$

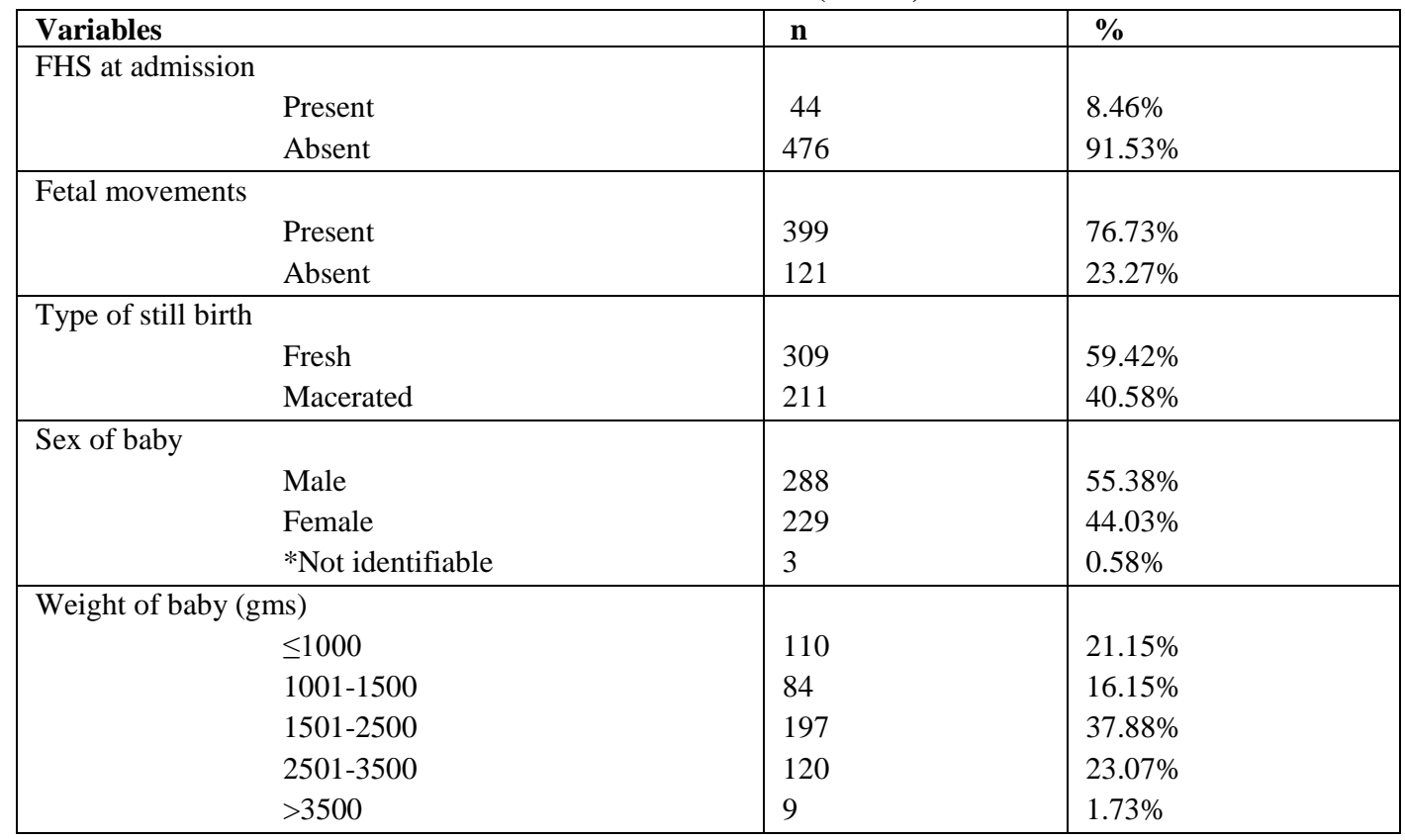

* In cases with extreme prematurity and maceration

Table 4: Causes of antepartum/intratartum stillbirths $(\mathrm{N}=520)$

\begin{tabular}{|c|c|c|c|c|c|c|}
\hline \multirow[t]{2}{*}{$\begin{array}{l}\text { *Cause of fetal death } \\
\text { assigned }\end{array}$} & \multicolumn{2}{|c|}{$\begin{array}{l}\text { Fetal heart absent at } \\
\text { admission } n=476 \\
\text { (antepartum SB) }\end{array}$} & \multicolumn{2}{|c|}{$\begin{array}{l}\text { Fetal heart present at } \\
\text { admission } n=44 \\
\text { (intrapartum SB) }\end{array}$} & \multicolumn{2}{|c|}{$\begin{array}{l}\text { Total stillbirths } \\
\mathbf{N}=\mathbf{5 2 0}\end{array}$} \\
\hline & $\mathbf{N}$ & $\%$ & $\mathbf{n}$ & $\%$ & $\mathbf{N}$ & $\%$ \\
\hline $\begin{array}{l}\text { Maternal infections- } \\
\text { Hepatitis } \\
\text { Chorioamnionitis } \\
\text { Syphilis } \\
\text { HIV } \\
\text { Rubella } \\
\text { Other infections }\end{array}$ & $\begin{array}{c}4 \\
87 \\
1 \\
2 \\
1 \\
10\end{array}$ & $\begin{array}{c}0.77 \% \\
16.73 \% \\
0.19 \% \\
0.38 \% \\
0.19 \% \\
1.92 \%\end{array}$ & $\begin{array}{l}1 \\
0 \\
0 \\
0 \\
0 \\
3\end{array}$ & $\begin{array}{c}0.19 \% \\
0 \% \\
0 \% \\
0 \% \\
0 \% \\
0.57 \%\end{array}$ & $\begin{array}{c}5 \\
87 \\
1 \\
2 \\
1 \\
13\end{array}$ & $\begin{array}{c}0.96 \% \\
16.73 \% \\
0.19 \% \\
0.38 \% \\
0.19 \% \\
2.50 \% \\
\end{array}$ \\
\hline $\begin{array}{l}\text { Intrapartum causes- } \\
* * \text { Malpresentations } \\
\text { Prolonged labor } \\
\text { Obstructed labor } \\
\text { Fetal distress } \\
\text { Rupture uterus }\end{array}$ & $\begin{array}{l}4 \\
3 \\
6 \\
- \\
4\end{array}$ & $\begin{array}{c}0.77 \% \\
0.57 \% \\
1.15 \% \\
- \\
0.77 \% \\
\end{array}$ & $\begin{array}{l}0 \\
1 \\
1 \\
7 \\
2\end{array}$ & $\begin{array}{c}0 \% \\
0.19 \% \\
0.19 \% \\
4.04 \% \\
0.38 \% \\
\end{array}$ & $\begin{array}{l}4 \\
4 \\
7 \\
7 \\
6\end{array}$ & $\begin{array}{l}0.77 \% \\
0.77 \% \\
1.34 \% \\
1.34 \% \\
1.15 \% \\
\end{array}$ \\
\hline $\begin{array}{l}\text { Fetal causes- } \\
\text { Birth defects } \\
\text { Hydrops } \\
\text { Extreme prematurity } \\
\text { IUGR (severe) } \\
\text { Multiple pregnancy }\end{array}$ & $\begin{array}{c}15 \\
0 \\
101 \\
27 \\
20\end{array}$ & $\begin{array}{c}3.46 \% \\
0 \% \\
19.42 \% \\
5.19 \% \\
3.84 \%\end{array}$ & $\begin{array}{l}6 \\
1 \\
5 \\
2 \\
1\end{array}$ & $\begin{array}{l}1.15 \% \\
0.19 \% \\
0.96 \% \\
0.38 \% \\
0.19 \%\end{array}$ & $\begin{array}{c}21 \\
1 \\
106 \\
29 \\
21\end{array}$ & $\begin{array}{c}4.04 \% \\
0.19 \% \\
20.38 \% \\
5.57 \% \% \\
4.04 \% \\
\end{array}$ \\
\hline $\begin{array}{l}\text { Cord complications- } \\
\text { Abnormal insertion } \\
\text { Knots } \\
\text { Loops } \\
\text { Cord prolapsed }\end{array}$ & $\begin{array}{c}1 \\
3 \\
14 \\
10\end{array}$ & $\begin{array}{l}0.19 \% \\
0.57 \% \\
2.69 \% \\
1.92 \%\end{array}$ & $\begin{array}{l}0 \\
0 \\
1 \\
0\end{array}$ & $\begin{array}{c}0 \% \\
0 \% \\
0.19 \% \\
0 \%\end{array}$ & $\begin{array}{c}1 \\
3 \\
15 \\
10\end{array}$ & $\begin{array}{l}0.19 \% \\
0.57 \% \\
2.88 \% \\
1.92 \%\end{array}$ \\
\hline $\begin{array}{l}\text { Placental causes - } \\
\text { Abruption } \\
\text { Placenta praevia }\end{array}$ & $\begin{array}{c}48 \\
7\end{array}$ & $\begin{array}{l}9.23 \% \\
1.34 \%\end{array}$ & $\begin{array}{l}5 \\
2\end{array}$ & $\begin{array}{l}1.15 \% \\
0.38 \%\end{array}$ & $\begin{array}{c}53 \\
9\end{array}$ & $\begin{array}{c}10.19 \% \\
1.73 \%\end{array}$ \\
\hline $\begin{array}{l}\text { Maternal causes - } \\
\text { Hypertensive disorders } \\
\text { Diabetes } \\
\text { Cholestasis } \\
\text { Trauma } \\
\text { Unexplained }\end{array}$ & $\begin{array}{c}78 \\
9 \\
11 \\
1 \\
266\end{array}$ & $\begin{array}{c}15.0 \% \\
1.73 \% \\
2.11 \% \\
0.19 \% \\
51.15 \%\end{array}$ & $\begin{array}{c}4 \\
0 \\
4 \\
0 \\
11\end{array}$ & $\begin{array}{c}0.77 \% \\
0 \% \\
0.77 \% \\
0 \% \\
2.11 \%\end{array}$ & $\begin{array}{c}82 \\
9 \\
15 \\
1 \\
277\end{array}$ & $\begin{array}{c}15.77 \% \\
1.73 \% \\
2.88 \% \\
0.19 \% \\
53.27 \%\end{array}$ \\
\hline
\end{tabular}

*Most of the women had more than one cause of death e.g. a hypertensive woman had abruption, severe IUGR and loop of cord. ** Malpresentations was found in 89 cases, but cause of stillbirths was assigned in only 4. Mild IUGR (n=20) \& anemia (n=187) were not assigned as cause for stillbirth. 
Table 5: Surrogate markers of antepartum / intrapartum fetal deaths

\begin{tabular}{|l|l|l|}
\hline Parameters & Antepartum stillbirth & Intrapartum stillbirth \\
\hline FHS (gold standard) & 476 (FHS absent) & 44 (FHS present) \\
\hline Surrogate markers- & 399 (FM absent) & $\begin{array}{l}\text { 121(FM present) } \\
\text { 1. *Fetal movements (FM) }\end{array}$ \\
$2 . * *$ Macerated /fresh stillbirths & 211 (macerated) & 309 (fresh) \\
\hline
\end{tabular}

Table 6: Agreement of surrogate markers with FHS (gold standard)

\begin{tabular}{|c|l|c|}
\hline S. No. & Comparative Parameters & Kappa value \\
\hline 1. & FM versus FHS & 0.683 \\
\hline 2. & Macerated/fresh stillborns versus FHS & 0.321 \\
\hline 3. & FM versus macerated/fresh stillborns & 0.173 \\
\hline
\end{tabular}

\section{Discussion}

During the study period, there were 28,580 deliveries , out of which 520 stillbirths occurred making the average stillbirth rate 18.19 per 1000 total births which was higher compared to a study by Dandona $\mathrm{R}$ et al in an Indian state where a SBR of 15.4/1000 births has been reported during $2017^{[9]}$. However, SBR in our study was quite low compared to a study at a tertiary hospital in Brazil in 2017, where a SBR of 21.6 has been reported ${ }^{[10]}$.

A downward trend in the SBR was observed, being $22.86 \%, 15.55 \%$ and $14.51 \%$ in the year 2016, 2017 and 2018 respectively (Table 1, Fig 1). This average annual reduction in SBR of $2.78 \%$ was quite encouraging for achieving a SBR of less than 10 per 1000 births by 2030 as per India Newborn Action Plan (INAP) ${ }^{[11]}$. In a study at a tertiary hospital of North India over 10 years (2007-2016) an average annual reduction rate of only $1 \%$ has been reported ${ }^{[12]}$.

Advanced maternal age has been reported as an independent risk factor for stillbirths. The stillbirth risk doubled at age 35 years compared with 25-29 years age ${ }^{[13]}$. However, our study revealed maximum stillbirths $(55 \%)$ in the age group of 20 25 years and only 7 out of 520 women with stillbirths were more than 35 years of age (Table 2). This is because most of the women visiting our facility completed their family before 35 years of age. The direct effect of maternal aging is said to be related to low uteroplacental perfusion caused by poor uterine vasculature in older women. Certain risk factors for stillbirths can be attributed to chronic diseases, and medical or obstetric complications i.e. pregnancy-induced hypertension or gestational diabetes with increasing maternal age. Congenital fetal abnormalities is an important risk factor with increased maternal age. The association between stillbirth and maternal age disappears when congenital anomalies are excluded ${ }^{[14]}$.

Most of the women in our study were multigravidas (59.61\%) (Table 2). Frequent pregnancies deplete the nutritional status of the mother leading to adverse fetal outcomes. Zero parity and parity $>3$ were both associated with increased stillbirth risk ${ }^{[15]}$ suggesting a U-shaped relation between parity and risk of stillbirth ${ }^{[14]}$. Only 5 women $(0.96 \%)$ in our study were > para 3 (Table 2). Increasing access to family planning services, and improved socioeconomic status appears to have brought down the number of women with parity $>3$ in our study population.

It has been documented that women with no prenatal care had significant increased risk of stillbirths ${ }^{[15]}$ and is a determinant factor associated with the occurrence of fetal deaths ${ }^{[10]}$. Similar results were revealed in our study that $54.81 \%$ of women were unbooked and had no or inadequate prenatal care (Table2). This is a potentially modifiable factor. Availability and access to these services can attenuate the stillbirth rates.
Maximum incidence of intrauterine fetal deaths in this study were at gestational age of 33-37 weeks (34.61\%). These third trimester stillbirths might be because of certain conditions remained undiagnosed i.e. congenital malformations, infections, antepartum haemorrhage, cord prolapse, preeclampsia and diabetes in women with no or inadequate prenatal care. In the WHO Antenatal trial ${ }^{[16]}$ the peak in deaths during 38 weeks was perhaps due to reduced number of visits ${ }^{[17]}$. Having only two or three visits scheduled in the third trimester cannot be sufficient to detect fetuses at risk or to provide treatment to prevent stillbirths, contributing to increased risk of perinatal deaths in the reduced antenatal care group ${ }^{[18]}$.

\section{Causes of still births:}

Extreme prematurity was the commonest cause attributed to stillbirths in our study $(\mathrm{n}=106,20.38 \%)$. Devi et al observed a very high incidence of $42.92 \%$ stillbirths due to extreme prematurity with fetal weight $<1000 \mathrm{gm}^{[19]}$. Infection is another important cause of stillbirths worldwide: in low-income and middle-income countries, $50 \%$ of stillbirths or more are probably caused by infection. By contrast, in high-income countries only $10-25 \%$ of stillbirths are caused by infection [Goldenberg] ${ }^{[20]}$. In our study, infection was responsible for $20.95 \%$ of stillbirths. Chorioamnionitis with foul smelling liquor was seen in $16.73 \%$ $(\mathrm{n}=87)$ cases. A quite high rate of chorioamnionitis was reported in $82 \%$ cases of stillbirths by Tolockiene et al ${ }^{[21]}$. Hypertensive disorders were associated with stillbirth in $15.77 \%(n=82)$ in our study. Similar observation has been made by Jamal $\mathrm{S}$ et al ${ }^{[22]}$. Among the placental causes, abruption was found in $10.19 \%$ $(n=53)$ cases. Loop/loops of cord around neck, cord prolapse and true knots, abnormal insertion contributed to $5.56 \%$ of stillbirths. Out of 49 women with IUGR, severe IUGR contributed to $5.57 \%$ $(n=29)$ stillbirths in our study. It has been documented that both SGA and LGA are associated with stillbirths ${ }^{[23]}$. Congenital anomalies accounted for 21 deaths (4.04\%), anencephaly alone being the cause in 10 cases. Lawn et al has reported that congenital abnormalities account for a median of $7.4 \%$ of all stillbirths some of which are preventable, notably neural tube defects ${ }^{[3]}$. Cigarette smoking during pregnancy is a potentially preventable cause of adverse pregnancy outcomes including stillbirth ${ }^{[24]}$. However, we did not encounter any such patient. The cause for stillbirth remained unexplained in $53.27 \%(\mathrm{n}=277)$ in our study which was quite high, compared to $23.6 \%$ reported by Modelli et al ${ }^{[6]}$. The study was limited by the absence of fetal autopsy which could have been very helpful in determining the cause. Anemia was found to be associated in $35.96 \%$ patients in our study, though it was not assigned as a cause for stillbirth in any case. In a study by Singh R et al, women with severe anemia did not have any stillbirths ${ }^{[25]}$.

\section{Intrapartum stillbirths:}


Most of the intrapartum deaths are considered preventable with good obstetric care during delivery. A systematic review indicated that $25-67 \%$ stillbirths are primarily due to preventable intrapartum complications ${ }^{[26]}$. We had $44(8.46 \%)$ intrapartum stillbirths where fetal heart was present at admission (Table 5) which was less than the reported $10 \%$ incidence of intrapartum still births in developed countries ${ }^{[27]}$. Martin et al estimated $13.9 \%$ stillbirths in intrapartum period ${ }^{[10]}$. In India, 46.4\% intrapartum stillbirths have been reported in Bihar state by Dandona $\mathrm{R}$ et al ${ }^{[9]}$.

Among intrapartum causes, fetal distress was found in 7 cases, abruption and hypertensive diseases were found in 5 and 4 cases respectively. In 6 women diagnosed with rupture uterus, only 2 had FHS present at admission (intrapartum deaths) (Table 4). Obstructed labor is an intrapartum event yet only 1 case of obstructed labor out of 7 cases had FHS present at the time of admission and was included in intrapartum deaths; rest 6 reported quite late in labor with absent FHS.

\section{Surrogate markers of intrapartum fetal deaths}

Fresh stillborns occurred in 59.42\% ( $\mathrm{n}=309)$ cases (Table 3,5), similar to that reported by Rajagopal et al $(51.7 \%)^{[28]}$. Fresh stillbirth is considered a surrogate marker of intrapartum fetal death but, in our study there was a high disparity between fresh still births $(n=309)$ and intrapartum stillbirths $(n=44)($ Table 3,5). This disparity might be because of our institute being a tertiary and a referral hospital many women arrived late in the hospital after being referred from other hospitals, sometimes after multiple referrals and it was difficult to assess the fetal heart status at the start of labor. In 11 case of prolonged and obstructed labor in our study, only 2 had FHS present at admission. Rest of 9 had absent FHS (antepartum death), yet delivered a fresh stillbirth. Similarly abruption of placenta occurred in 53 women out of which 48 women had absent FHS at admission, and 39 women delivered a fresh stillborn. As fresh stillbirths can occur when fetus dies 6 to 12 hours before labor and during labor, therefore, it can be presumed that most of fresh stillbirths in our study occurred in $<12$ hours before labor. Therefore, fresh stillbirth does not appear to be a good surrogate marker for intrapartum fetal death. Only a fair agreement existed between macerated/fresh stillborn and FHS in our study (kappa value 0.321) (Table 6).

Fetal movements, another surrogate marker of antepartum deaths, were absent in our study in 399 (76.73\%) women, comparable to $75.8 \%$ as reported by Jamal S et al ${ }^{[22]}$ and Tamrakar SR et al who reported reduced or absent fetal movements in 54.7\% cases ${ }^{[29]}$. We had 476 (91.53\%) women with absent FHS at admission in labor ward (antepartum stillbirths) though only 399 (76.73\%) women complained absent fetal movements (Table 5). A substantial agreement (kappa value 0.683 ) between fetal movement and FHS was seen in our study. Therefore, fetal movements are a better surrogate marker for antepatum / intrapartum deaths compared to macerated /fresh stillbirths (kappa value 0.321) (Table 6). Therefore daily fetal movement counting is important.

Daily fetal movement count has $87.5 \%$ sensitivity, $94.1 \%$ specificity, $43.7 \%$ positive predictive value and $99.3 \%$ negative predictive value chart in prediction of the risk of intrauterine fetal death as reported by De Muylder ${ }^{[30]}$. In a study by Dandona R et al, $6.2 \%$ stillbirths remained unclassified where a surrogate marker of fetal movements present maximum 8 hours prior to labor was taken for classifying as intrapartum / antepatum deaths ${ }^{[9]}$.

\section{Prevention strategies for stillbirths}

\section{Pre-conception and antenatal care:}

A significant number of stillbirths are preventable. Health interventions must start well before conception and during antenatal period for improved perinatal outcome. Prenatal counseling, screening and interventions for co-morbidities with counseling for regular antenatal check-ups are important in reducing stillbirths. Adolescent pregnancies have 50\% increased risk of stillbirths. Inter-pregnancy intervals less than 12 months or longer than 60 months have been linked to adverse perinatal outcomes.

\section{Interventions}

1. Dietary interventions- Maternal nutritional status is one of the factors significantly associated with stillbirth. Balanced energy protein intake improves fetal growth and reduces the risk of fetal and neonatal death ${ }^{[31]}$. Folic acid supplementation before and early pregnancy reduces the risk of neural tube defects and related stillbirths. Micronutrient supplements in pregnancy improves fetal growth, development, birthweight and maternal complications. Zn supplementation reduces preterm labor (PTL) by $14 \%$. Increased dietary intake of vitamin $\mathrm{C}$ has been associated with increase in birthweight and placental weight. Vitamin $\mathrm{E}$ has a preventive effect on many pregnancy complications i.e. pre-eclampsia (PE), growth restriction, preterm premature rupture of membranes. Calcium supplementation is associated with reduced PE. Magnesium deficiency has been linked with PE and PTL. Vitamin D supplements in pregnancy is associated with reduced risk of PE, low birth weight and $\mathrm{PTL}^{[32]}$.

Iron and folic acid supplementation during pregnancy besides preventing maternal anemia also improves perinatal outcome of the pregnancy ${ }^{[32]}$. The Ministry of Health and Family Welfare, Govt. of India has IFA supplementation programme which provides 1 tablet containing $100 \mathrm{mg}$ elemental iron and $500 \mathrm{mcg}$ folic acid daily from 14-16 weeks and continuing 100 days post partum ${ }^{[33]}$.

2. Prevention and management of infections- It is reported that in developed countries 10 and $25 \%$ of all stillbirths were associated with infections ${ }^{[34]}$. TORCH infections, malaria, syphilis, varicella-zoster, parvovirus B19 are a leading cause of stillbirths worldwide. Examination of placentas from live and stillborn infants found evidence of inflammation in $30.4 \%$ of stillbirths compared with $12 \%$ of controls ${ }^{[35]}$. Chorioamnionitis a risk factor for stillbirths should be identified and treated promptly.

3. Prevention, detection and management of other comorbidities- Appropriate screening /diagnosis, medical management and timely delivery can reduce many stillbirths associated with comorbidities. Aspirin for prevention and anti-hypertensives and magnesium sulphate for management of PE /eclampsia has been recommended ${ }^{[36]}$. Stillbirths associated with pregestational or gestational diabetes can be greatly reduced by strict control of blood sugar levels throughout pregnancy. Control of pregestational diabetes before or in early pregnancy can avoid stillbirths associated with congenital abnormalities. Post-dated pregnancies should be monitored closely. Incidence of stillbirth increases from 39 weeks onwards with a sharp rise after 40 weeks of gestation ${ }^{[37]}$. 
4. Screening and management of fetal growth and well being- Delay in the diagnosis of intrauterine growth restriction (IUGR) may lead to stillbirth. Diagnosis of IUGR can be done by fundal height measurement or ultrasound biometry. Doppler velocimetry measures blood flow dynamics in uterine, umbilical, and fetal arteries ${ }^{[38]}$ and are helpful in deciding termination of pregnancy in these cases, decreasing the risk of stillbirths. Antenatal ultrasound can also diagnose many fetal congenital abnormalities and cord abnormalities.

Fetal hypoxia or compromise can lead to reduction in fetal movements, which can be identified by the pregnant women. Increased vigilance towards maternal perception of movements reduces SBR ${ }^{[39]}$.

\section{Intrapartum care and Labor management:}

Care during labor and childbirth have the potential to reduce stillbirths by a third. Routine use of partogram, NST, early referral and timely intervention can prevent these stillbirths. In our study, in some cases we found lacunae in health care system. Primary health care providers contributed to suboptimal care by failure to recognize high-risk cases, leading to late referrals \& poor counselling. Suboptimal care by obstetricians included failure to identify and manage high risk cases, delay/error in labor management and timely intervention, unavailability of equipment for cardiotocography. Lastly, perinatal death audits in the hospital also helped to identify many flaws in our clinical management.

\section{Prevention strategies at the level of community and family:}

Socio-cultural and community attributes e.g. status of women, caste, class, geography, residence, income, etc. affect fetal outcomes. Individual attributes - birth order, previous birth intervals, mother's age at marriage, conception are also important ${ }^{[11]}$. Family-centered approaches and women supported by health care providers can encourage and improve both maternal health and reduction in fetal deaths ${ }^{[10]}$.

\section{Prevention at the level of policy makers:}

Illiteracy, low socioeconomic status and unawareness of the importance of regular antenatal visits contribute indirectly to high rates of stillbirth and requires strengthening at grass root level. Janani Suraksha Yojna launched by the Ministry of Health and Family Welfare of the Government of India under National Rural Health Mission and Janani Shishu Suraksha Karyakram have been adopted by our institute which provide zero expense delivery, free drugs and consumables, free diagnostics, free diet during hospital stay to pregnant women.

\section{Conclusions}

Neither all stillbirths are preventable, nor can a cause be assigned in all cases. Many a times, multiple factors are responsible for stillbirth. In this study, extreme prematurity was the most common assigned cause of stillbirths followed by chorioamnionitis. Fetal movements have been found to be a better surrogate marker than macerated/fresh stillborn for antepartum/intrapartum deaths.

\section{Ethics Approval and Consent to Participate}

The study was approved by ethical committee of the institute. Being a retrospective study, data was collected from the indoor records of patients, hence consent was not required.

\section{List of Abbreviations}

SBR: Stillbirth Rate, SB: Stillbirth, FHS: Fetal Heart Sound, PE: Pre-eclampsia, IUGR: Intrauterine Growth Restriction, PTL: Premature Labor, NST: Non Stress Test, FM: Fetal Movement, SGA: Small for Gestational Age, LGA - Large for Gestational Age

Data Availability: The data presented in this study is available with all the authors

\section{Conflict of Interest: None}

Funding Statement: Institutional funding

Authors' Contribution: Dr. Ojasvi - Data collection, writing preliminary draft; Dr. Vandana - supervised the project and verified the data collection; Dr. Mamta - Study design, final draft All authors provided the critical feedback for the final manuscript

Acknowledgement: We are thankful to Dr. Zeeshan Zaidi for helping us in the statistics work.

\section{References}

[1] World Health Organization. International Classification of Diseases 10th revision (ICD10). http://wwwwhoint/classifications/icd/ICD10Volume2_en _2010pdf?ua=1 2010.

[2] Richardus JH, Graafmans WC, Verloove-Vanhorick SP, Mackenbach JP. The perinatal mortality rate as an indicator of quality of care in international comparisons. Med Care. 1998;36(1):54-66. doi:10.1097/00005650199801000-00007

[3] Lawn JE, Blencowe H, Waiswa P, et al. Stillbirths: rates, risk factors, and acceleration towards 2030. Lancet 2016;387:587-603.

[4] PMNCH Fact sheet: Stillbirths. Available at https://www.who.int/pmnch/media/press_materials/fs/20 1106_stillbirths/en/

[5] WHO. Global Health Observatory data Repository. Available https://apps.who.int/gho/data/viesw.main.GSWCAH06v

[6] Modelli MES, Souza ABP, Costa MKR. Stillbirths: An underestimated and neglected reality. J For Med and Leg $\begin{array}{llll}\text { Aff. } & \text { 2016; } & \text { 1(2):110. }\end{array}$ http://dx.doi.org/10.19104/jfml.2016.109

[7] Gold KJ, Abdul-Mumin AR, Boggs ME, Opare-Addo HS, Lieberman RW. Assessment of "fresh" versus "macerated" as accurate markers of time since intrauterine fetal demise in low-income countries. Int J Gynaecol Obstet. 2014;125(3):223-227. doi:10.1016/j.ijgo.2013.12.006

[8] McClure EM, Saleem S, Goudar SS, Moore JL, Garces $\mathrm{A}$, Esamai $\mathrm{F}$ et al . Stillbirth rates in low-middle income countries 2010 - 2013: a population-based, multi-country study from the Global Network. Reprod Health. 2015;12 Suppl 2(Suppl 2):S7. doi: 10.1186/1742-4755-12-S2-S7. Epub 2015 Jun 8.

[9] Dandona, R., Kumar, G.A., Akbar, M. et al. Deferred and referred deliveries contribute to stillbirths in the Indian state of Bihar: results from a population-based survey of all births. BMC Med 17, 28 (2019).

[10] Martins MCF, Feitosa FEdL, Viana Júnior AB, Correia LL, Ibiapina FLP, Pacagnella RdC, et al. (2019) Pregnancies with an outcome of fetal death present higher risk of delays in obstetric care: A case-control 
study. PLoS ONE 14(4): e0216037. https://doi.org/10.1371/journal.pone.0216037

[11] INAP Ministry of Health and Family Welfare, Government of India. INAP: India newborn action plan. New Delhi: Government of India; September 2014. Available https://www.newbornwhocc.org/INAP_Final.pdf

[12] Sharma B, Prasad GRV, Aggarwal N, Siwatch S, Suri V, Kakkar N. Aetiology and trends of rates of stillbirth in a tertiary care hospital in the north of India over 10 years: a retrospective study. BJOG 2019; 126 (S4): 14-20.

[13] Waldenström U, Cnattingius S, Norman M, Schytt E. Advanced Maternal Age and Stillbirth Risk in Nulliparous and Parous Women. Obstet Gynecol. 2015; 126(2):355-62.

[14] Gardosi J, Madurasinghe V, William M, Malik A, Francis A Maternal and fetal risk factors for stillbirth: population based study.: BMJ 2013;346:f10

[15] Saleem S, Tikmani SS, McClure EM, Moore JL, Azam SI, Dhaded SM, et al. Trends and determinants of stillbirth in developing countries: results from the Global Network's Population-Based Birth Registry. Reprod Health 15, 100 (2018). https://doi.org/10.1186/s12978018-0526-3

[16] Lavin T, Pattinson RC. Does antenatal care timing influence stillbirth risk in the third trimester? A secondary analysis of perinatal death audit data in South Africa. BJOG. 2018;125(2):140-147.

[17] Vogel JP, Habib NA, Souza JP, Gulmezoglu AM, Dowswell T, Carroli G, et al. Antenatal care packages with reduced visits and perinatal mortality: a secondary analysis of the WHO Antenatal Care Trial. Reprod Health. 2013; 10: 19.

[18] Dowswell T, Carroli G, Duley L, Gates S, Gulmezoglu AM, Khan-Neelofur D, et al. Alternative versus standard packages of antenatal care for low-risk pregnancy. Cochrane Database Syst Rev 2015; 7: CD000934.

[19] Devi KS, Aziz N, Gala A, Surapaneni T, Nair DH, Pant HB. Incidence of stillbirths and risk factors at a tertiary perinatal center in Southern India: retrospective observational study. Int $\mathrm{J}$ Gynecol and Reprod Sci. (2018);1(1):14-22.

[20] Goldenberg RL, McClure EM, Saleem S, Reddy UM. Infection-related stillbirths. Lancet 2010; 375: 1482-90

[21] Tolockiene E, Morsing E, Holst E, Herbst A, Ljungh A, Svenningsen $\mathrm{N}$ et al. Intrauterine infection may be a major cause of stillbirths in Sweden. Acta Obstet Gynecol Scand 2001; 80: 511-518.

[22] Jamal S, Agarwal S. IUFD incidence, causes and complications: a retrospective study done at a tertiary care centre in greater Noida, India. Int $\mathrm{J}$ Reprod Contracept Obstet Gynecol 2017;6:5483-7

[23] Bukowski R, Hansen NI, Willinger M, Reddy UM, Parker CB, Pinar $\mathrm{H}$ et al. Fetal growth and risk of stillbirth: a population-based case-control study. PLoS Med. 2014;11(4):e1001633. Published 2014 Apr 22. doi:10.1371/journal.pmed.1001633

[24] Wisborg K, Kesmodel U, Henriksen TB, Olsen SF, Secher NJ. Exposure to Tobacco Smoke in Utero and the Risk of Stillbirth and Death in the First Year of Life. American Journal of Epidemiology. 2001; 154 (4): 322327. https://doi.org/10.1093/aje/154.4.322
[25] Singh R, Gupta M \& Saini V. Women with Severe Anemia in Labor: Adverse Clinical Outcomes. International Journal of Innovative Research in Medical Science. 2019; 4(01), 33 to 39 . https://doi.org/10.23958/ijirms/vol04-i01/530

[26] Lawn J, Shibuya K, Stein C. No cry at birth: global estimates of intrapartum stillbirths and intrapartumrelated neonatal deaths. Bull World Health Organ. 2005;83(6):409-17.

[27] WHO. Maternal, newborn, child and adolescent health. Available at: https://www.who.int/maternal_child_adolescent/epidemi ology/stillbirth/en/

[28] Rajagopal VM, Betha K, Priya GS. Classification of stillbirth by relative condition at death (Re Co De) at various trimesters of pregnancy: a rural tertiary teaching hospital based study. Int J Reprod Contracept Obstet Gynecol 2017;6:3550-5.

[29] Tamrakar SR, Chawla CD. Intrauterine Foetal Death and Its Probable Causes: Two Years' Experience in Dhulikhel Hospital - Kathmandu University Hospital Kathmandu University Hospital. Kathmandu Univ med J. 2012;10(4):44-8.

[30] De Muylder X. The kick chart in high-risk pregnancies: a two-year experience in Zimbabwe. Int $\mathrm{J}$ Gynaecol Obstet. 1988;27(3):353-7.

[31] Ota E, Tobe-Gai R, Mori R, Middleton P,Flenady V. Interventions during the antenatal period for preventing stillbirth: an overview of Cochrane systematic reviews. Protocol Version published: 18 January 2012. https://doi.org/10.1002/14651858.CD009599

[32] Mousa A, Naqash A, Lim S.Macronutrient and Micronutrient Intake during Pregnancy: An Overview of Recent Evidence.Nutrients. 2019 Feb 20;11(2):443. doi: 10.3390/nu11020443

[33] Guielines for control of iron deficiency anemia. National iron +initiative. Ministry of Health and Family Welfare. Govt. of India. Available at: https://www.nhm.gov.in/images/pdf/programmes/childhealth/guidelines/Control-of-Iron-DeficiencyAnaemia.pdf

[34] McClure EM, Goldenberg RL. Infection and stillbirth. Semin Fetal Neonatal Med (2009) 14(4):182-9. doi:10.1016/j.siny.2009.02.003

[35] Blackwell C. The role of infection and inflammation in stillbirths: parallels with SIDS? Front. Immunol., 09 June 2015 | https://doi.org/10.3389/fimmu.2015.00248

[36] Roberts JM, August PA, Bakris G, Barton JR, Bernstein IM, Druzin M, et al. Hypertension in Pregnancy. Report of the American College of Obstetricians and Gynecologists' Task Force on Hypertension in Pregnancy. Obstetrics \& Gynecology. 2013; 122(5):1122-31.

[37] Galal M, Symonds I, Murray H, Petraglia F, Smith R. Postterm pregnancy. Facts Views Vis Obgyn. 2012;4(3):175-87.PMID: 24753906

[38] Sumangali PK, Omana EK, Nambiar SS. Doppler velocimetry of umbilical, and middle cerebral arteries in the prediction of fetal outcome. Int $\mathrm{J}$ Res Med Sci 2017;5:4789-92.

[39] Frøen JF. A kick from within--fetal movement counting and the cancelled progress in antenatal care. J Perinat Med. 2004;32(1):13-24. doi:10.1515/JPM.2004.003 